\title{
Editorial: Statements, declarations and the problems of ethical expertise
}

Ethical expertise remains a contested concept, for various reasons. To begin with, all individuals are experts in a way. Whereas an "epistemological rupture" divides everyday weather forecasting by lay people from the pursuits of professional meteorologists, this is different in the case of ethics. Virtually all ethical theories explicitly regard non-professionals as autonomous persons who are capable of making valid moral judgements and of understanding and applying ethical principles in appropriate ways. In his article on public involvement in biobank governance in this issue, Bjørn Myskja addresses this debate in terms of a rehabilitation of lay expertise in the context of the "legitimation crisis" of professionalism. ${ }^{1}$

According to Myskja, this crisis has lead to an interest in the particular knowledge lay people possess, as well as to a "tendency to argue that lay knowledge can be every bit as valuable as professional knowledge". Although this tendency is noticeable with regard to other types of expertise as well, it notably seems to apply to ethics. Although ethical expertise clearly has a role to play - as an archive of information on how issues have been dealt with in previous cases, for instance, or as a toolbox for testing the validity of arguments - from an outsider's perspective, the validity and import of ethical knowledge is far from obvious. Moreover, as bioethics journals reveal, ethical experts seem to disagree at least as much among themselves as the infamous doctors did in the comedies by Molière, long before medicine became an (evidence-based) science.

Another reason why ethical expertise remains contested is that ethics is practised on various levels by various kinds of actors. Besides the community of (bio)ethicists representing ethics as an academic discipline with journals, grant proposals, peerreviews and conferences, nationally as well as internationally, there is another form of institutionalised and professionalized ethics, namely ethics as it is practised in the context of ethics committees, locally, nationally and internationally. Many of those who contribute to this process have never been formally trained in ethics, beyond a "short course" level, and much has been written (and many concerns have been raised) concerning the quality of the work of these committees, notably on local levels.

In an era of globalisation, however, where technosciences such as genomics are spreading quickly worldwide, another level of ethical discourse becomes especially important - the level of international institutions, where policy conferences are organised and statements and declarations drafted and published. Globalisation of bioethics, of the $E$ in ELSA so to speak, seems an inevitable response to the globalisation of the technoscientific culture. It is part of international science governance, and international institutions can be expected to play their role. But once again, we are faced with a highly controversial practice.

Take for example some of the declarations that have been issued by UNESCO, such as The Human Genome and Human Rights and the Declaration on Bioethics and 
Human Rights. The latter document has been fiercely (and, as I will argue, unfairly) criticised by academic bioethicists, notably in a special issue of Developing World Bioethics. ${ }^{2}$ One criticism is that the concepts used in this document are too general and vague to generate real commitment. Another is that the "values claimed to be universal in this document are, in actual fact, nothing of the sort" (p. iv), and this notably applies to concepts such as "human rights" and "dignity". Once again, we are reminded of Molière's doctors who seem incapable to agree even (or especially) when it comes to the validity and meaning of their core concepts.

A third important criticism raised by the journal's editors, is that UNESCO is actually trespassing on other people's domains. In their opinion, UNESCO is not supposed to set up such declarations at all. For example, they argue that "whole articles deal with matters of informed consent in biomedical research and therapeutic practice. It is entirely unclear why UNESCO should concern itself with such a matter" (p. iii). Such activities, they write, are the domain of other organizations or, better still, should be left to the "professional bioethicists". In short, UNESCO is denied the competence and the qualification to discuss these things. This line of reasoning is not unlike the type of criticism bioethicists themselves often receive when they start "meddling" (as members of research ethics committees for instance) with affairs that, according to some, could better be left to the professionals (in this case, biomedical researchers). UNESCO is even blamed for publishing pamphlets (the obvious genre format of ethics in this level) instead of peer-reviewed articles. What seems to be denied is that, besides bioethics as an academic field, there may exist another legitimate level of ethical deliberation, with stylistic features, quality standards and objectives of its own.

Another example of an international platform engaged in this type of work is the HUGO ethics committee, chaired by Ruth Chadwick. This committee has published an impressive series of statements on core issues of the genomics ELSA domain, including DNA Sampling (1998), Cloning (1999), Benefit Sharing (2000), Gene Therapy Research (2001), Human Genomic Databases (2002) and Stem Cell Research (2004). Its latest statement, which we publish in this issue, concerns pharmacogenomics (PGx).

No doubt, the same kind of criticism that has been levelled at the UNESCO declaration could be directed towards this latter statement as well. Its core principles, such as "solidarity", "equity" and "beneficence", remain relatively vague. Moreover, one may question the extent to which these can really be regarded as universal, from a bioethics perspective. And so on. But to my mind such criticism does not do justice to the genre, to the type of document we are dealing with. Although the meanings of some of the key concepts used in this document have been elaborated in intricate ways by academic bioethicists in their journals, it must be acknowledged that, in this context, they play a somewhat different role. Statements and declarations contribute to the process of developing, through international dialogue on various levels and in various contexts, the basic framework of a universal bioethics. Its basic objective is to set up a network of concepts that may support the difficult but indispensable task of building international policies for science governance (and this includes genomics governance). At a time when genomics research is spreading globally at a high pace, this becomes an urgent task. I do not doubt that academic bioethics has an important 
GSP Genomics, Society and Policy

online 2007, Vol.3, No.1, pp.ii-iv

and critical contribution to make to this process. But the question of whether this type of document should be produced (or has a right to exist) at all seems somewhat too academic.

\section{Hub Zwart}

Radboud University Nijmegen, Centre for Society \& Genomics, the Netherlands

\footnotetext{
${ }^{1}$ B. Myskja. Lay expertise: Why involve the public in biobank governance? Genomics, Society and Policy 2007; 3 (1): 1-16.

${ }^{2}$ W. Landman and U. Schüklenk. Editorial. Developing World Bioethics 2007; 5 (3): iii-vi.
} 